\title{
BMJ Open Human resources and curricula content for early child development implementation: multicountry mixed methods evaluation
}

\author{
Maya Kohli-Lynch (D) ,, ${ }^{1,2}$ Victoria Ponce Hardy, ${ }^{1}$ Raquel Bernal Salazar, ${ }^{3,4}$ \\ Sunil S Bhopal (1) , ${ }^{5,6}$ Alexandra Brentani, ${ }^{7}$ Vanessa Cavallera, ${ }^{8}$ Esther Goh, ${ }^{9}$ \\ Jena D Hamadani, ${ }^{10}$ Rob Hughes, ${ }^{5,11}$ Karim Manji, ${ }^{12}$ Kate M Milner, ${ }^{1,13}$ \\ James Radner, ${ }^{14,15}$ Sonia Sharma, ${ }^{16}$ Karlee L Silver, ${ }^{17}$ Joy E Lawn, ${ }^{1}$ \\ Cally J Tann (1) 1,18,19
}

To cite: Kohli-Lynch M, Ponce Hardy V, Bernal Salazar R, et al. Human resources and curricula content for early child development implementation: multicountry mixed methods evaluation. BMJ Open 2020;10:e032134. doi:10.1136/ bmjopen-2019-032134

- Prepublication history and additional material for this paper are available online. To view these files, please visit the journal online (http://dx.doi. org/10.1136/bmjopen-2019032134).

Received 04 June 2019 Revised 13 February 2020 Accepted 12 March 2020
Check for updates

(c) Author(s) (or their employer(s)) 2020. Re-use permitted under CC BY-NC. No commercial re-use. See rights and permissions. Published by BMJ.

For numbered affiliations see end of article.

\section{Correspondence to} Dr Cally J Tann, MARCH Centre, London School of Hygiene \& Tropical Medicine, London, United Kingdom;

Cally.Tann@|shtm.ac.uk

\section{ABSTRACT}

Objective The WHO recommends responsive caregiving and early learning (RCEL) interventions to improve early child development (ECD), and to achieve the Sustainable Development Goals' vision of a world where all children thrive. Implementation of RCEL programmes in low and middle-income countries (LMIC) requires evidence to inform decisions about human resources and curricula content. We aimed to describe human resources and curricula content for implementation of RCEL projects across diverse LMICs, using data from the Grand Challenges Canada Saving Brains ECD portfolio.

Setting We evaluated 32 RCEL projects across 17 LMICs on four continents.

Participants Overall, 2165 workers delivered ECD interventions to 25909 families.

Intervention Projects were either stand-alone RCEL or RCEL combined with health and nutrition, and/or safety and security.

Primary and secondary outcomes We undertook a mixed methods evaluation of RCEL projects within the Saving Brains portfolio. Quantitative data were collected through standardised reporting tools. Qualitative data were collected from ECD experts and stakeholders and analysed using thematic content analysis, informed by literature review.

Results Major themes regarding human resources included: worker characteristics, incentivisation, retention, training and supervision, and regarding curricula content: flexible adaptation of content and delivery, fidelity, and intervention duration and dosage. Lack of an agreed standard ECD package contributed to project heterogeneity. Incorporation of ECD into existing services may facilitate scale-up but overburdened workers plus potential reductions in service quality remain challenging. Supportive training and supervision, inducement, worker retention, dosage and delivery modality emerged as key implementation decisions.

Conclusions This mixed methods evaluation of a multicountry ECD portfolio identified themes for consideration by policymakers and programme leaders relevant to RCEL implementation in diverse LMICs. Larger
Strengths and limitations of this study

- We analysed data from 32 responsive caregiving and early learning projects based in 17 low and middle-income countries, from the multicountry Saving Brains early child development portfolio, including data from a total of 2165 front-line workers who delivered interventions to over 25000 children and parents.

- Our mixed methods approach to this analysis enabled us to draw rich and varied conclusions from both quantitative project data and qualitative stakeholder interviews.

- Several process-related metrics, such as coverage, equity and cost-effectiveness, were not commonly reported by the projects and so were difficult to explore fully in this analysis.

- Impact data were not available for most projects at the time of the evaluation and so no assessment of impact was included.

- High heterogeneity within the Saving Brains portfolio presented challenges in drawing conclusions for individual project implementation.

studies, which also examine impact, including high-quality process and costing evaluations with comparable data, are required to further inform decisions for implementation of RCEL projects at national and regional scales.

\section{BACKGROUND}

Optimal early child development (ECD) is central to the Sustainable Development Goals' vision of a world in which children can thrive. ${ }^{12}$ ECD programmes have the potential to transform human capital across the life course, and scale-up of responsive caregiving and early learning (RCEL) is advocated by the WHO, UNICEF and World Bank, as a key part of the Nurturing Care Framework launched 
Box 1 Terms for responsive care and early learning for early child development

Multiple terms are used to describe interventions that promote early child development. The WHO, UNICEF and World Bank's Nurturing Care Framework refers to a spectrum of requirements necessary for reaching full developmental potential, including: good health, security and safety, nutrition, responsive caregiving and early learning.

In this paper, we use the concept of nurturing care, and specifically the term 'responsive care and early learning' (RCEL). RCEL describes the promotion of ECD through learning, play and caregiving that is responsive to children's needs. ${ }^{5647}$ Similar terms include 'responsive care/ caregiving', 'responsive stimulation', 'nurturing care', 'psychosocial stimulation', 'early learning' and 'play'.

in 2018 (see box 1). ${ }^{3-7}$ Programmes promoting RCEL have been found to be effective for ECD and related to longer term outcomes, including educational attainment and adult earnings. ${ }^{5} 8$

However, there are limited data to guide the practical implementation of RCEL programmes at scale in low and middle-income countries (LMIC), and a particular lack of data regarding human resources and curricula content. ${ }^{9-11}$ Additionally, guidance for contextual adaptation of projects is crucial but complex for RCEL which involves sectors beyond health. These gaps present challenges to decision-makers and may result in small-scale projects making design choices that limit the potential for sustainable scaling. ${ }^{51213}$ Thus, analysis of implementation factors for scaling of RCEL projects, particularly human resources and curricula content, is needed. ${ }^{9}$

The Lancet series 'Advancing Early Child Development: from Science to Scale ${ }^{14}$ and the Annals of the New York Academy of Sciences series 'Implementation Research and Practice for Early Childhood Development ${ }^{15}$ described gaps in the literature relating to ECD programming. The Archives of Diseases in Childhood series 'Informing design and implementation for early child development programmes ${ }^{, 16-20}$ provided evidence from the Grand Challenges Canada (GCC) Saving Brains portfolio for decision points related to ECD programming but did not specifically address human resources and curricula content. This paper responds to this gap, building on Radner et $a l$ s exploration of lessons learnt on scaling from the Saving Brains portfolio, to explore human resources and curricula content in a diverse range of RCEL programmes from the same portfolio. ${ }^{21}$ We predominantly use a health sector perspective, and contextualise our findings within learning from multicountry evaluations of communitybased maternal and newborn care and evaluations of mental health and nutrition programming.

\section{Aims and objectives}

This paper aims to describe human resources and curricula content for implementation of RCEL projects across diverse LMICs, using data from the Saving Brains portfolio. We will address who delivers the project, including training, supervision and inducement; and what the specific curricula content is, including materials, intensity, quality, fidelity and adaptation. Objectives are to:

1. Quantitatively analyse human resources and curricula content for RCEL projects in the Saving Brains portfolio.

2. Qualitatively analyse programme design and implementation decisions, focusing on themes related to human resources and curricula content.

3. Synthesise lessons learnt and implications for future design and implementation of RCEL programmes at scale.

\section{METHODS}

We took a mixed methods approach, incorporating quantitative data from an evaluation of projects in the Saving Brains portfolio alongside qualitative data from in-depth interviews (IDI) and focus group discussions (FGD) with ECD experts and Saving Brains project leads. Impact and outcome data were not available for the majority of projects at the time of the evaluation and were therefore not included in the evaluation.

\section{Overview of the Saving Brains portfolio evaluation}

Saving Brains is a diverse portfolio of projects, each aimed at improving ECD in LMICs through interventions in the first thousand days, as outlined by Radner et $a l^{21}$ Projects sought to improve brain development through preventing brain injury, promoting stimulating and responsive environments and/or protecting children from developmental risk factors. ${ }^{16}$ An evaluation of Saving Brains was undertaken in 2016-2017 by a team from the London School of Hygiene and Tropical Medicine in collaboration with the Saving Brains Platform team of experts, led by TruePoint Center/Harvard University and the WHO. ${ }^{22}$ The team evaluated 39 Saving Brains Seed and Transition-To-Scale (TTS) grants awarded between 2012 and 2016 to project leads from LMICs with variable design and implementation approaches (see Milner et al for summary of projects). ${ }^{16}$ Seed grants focused on demonstration of 'proof of concept' over 18-24 months while TTS grants focused on progression towards scale in partnership with other organisations over 3 years. The portfolio evaluation team developed a conceptual evaluation framework (online supplementary appendix figure A) based on the Medical Research Council Guidance on Evaluation of Complex Interventions and developed around a portfolio-level 'theory of change' (developed by Saving Brains Platform members) (online supplementary appendix figure B).$^{23}$ The conceptual evaluation framework provided a structure for the evaluation to systematically consider, describe and assess human resource and curricula content implementation factors. The evaluation team referred to the conceptual evaluation framework throughout the evaluation process to ensure comprehensive assessment of human resource and curricula content issues. The 'theory of change' metric indicators directly 
relate to Results-based Management and Accountability Framework (RMAF) data points collected by each project.

\section{Objective 1: quantitative data sources and analyses Quantitative data sources}

Quantitative data on project design and implementation were collected from GCC prespecified data collection tools (online supplementary appendix table A). Service Delivery Forms (SDF) comprised data regarding human resources and RCEL curricula and the RMAF comprised data on numbers of recipients and beneficiaries, child growth and development outcomes, parental and home environment outcomes, and funding, coverage and context of projects. Data were extracted from SDF and RMAF and imported into Microsoft Excel for cleaning, management and analysis (May to November 2016).

\section{Quantitative analysis}

Descriptive statistics relating to frequency and mode of outcome measurement across the portfolio were generated using Stata V.14 and Microsoft Excel. Data on occupation of workers delivering the RCEL projects were classified according to the International Standardised Classification of Occupations. ${ }^{24}$ For quantitative analysis, projects were grouped to highlight differences in implementation design factors. Groupings were as follows: (1) all RCEL projects, (2) stand-alone RCEL projects, and (3) integrated RCEL projects, where 'integrated projects' were integrated with another domain of the Nurturing Care Framework (other than RCEL) and 'standalone projects' were not.

\section{Objective 2: qualitative data sources and analyses \\ Literature review and topic guides}

IDI and FGD were facilitated using topic guides, which were developed based on a literature review guided by the Consolidated Criteria for Reporting Qualitative Research. The review explored implementation experiences relating to human resources and curricula content among ECD experts and Saving Brains project leads. Thematic areas of enquiry (online supplementary appendix table B) were established based on the literature, stakeholder consultation and analysis of written project proposals and progress reports submitted by project leads to GCC (online supplementary appendix table A). Our analysis was also informed by examples from the literature of similar efforts to support decision-making for implementation in other maternal and newborn health projects in LMICs.

Medline and Embase were searched, with the following MeSH terms: 'Child development' OR 'Developmental Disabilities' AND 'Developing Countries'. Additional articles were retrieved through reference lists of identified articles and publications from the Saving Brains community. Grey literature was searched via websites of major multilateral organisations engaged in ECD programming including the WHO, UNICEF, Save the Children Fund, the World Bank, World Vision International, other related organisations and Google.
Qualitative data inputs from key informant interviews and FGDs Key informants $(n=19)$ were ECD experts implementing ECD programmes in LMICs (online supplementary appendix table C). ECD experts were purposively selected from professional networks including national and international programmers and policymakers, ECD researchers, Saving Brains project leads and members of the Saving Brains Platform and GCC. All key informants were invited to participate by email. IDIs were conducted with key informants and FGD with Saving Brains project leads, with between 4 and 10 participants per FGD. All participants provided verbal informed consent and data collection was concluded once saturation was reached.

IDI and FGD were conducted in English (June to October 2016) and were audio recorded or transcribed by a member of the evaluation team. Each IDI lasted approximately 60 min while each FGD lasted between 60 and $90 \mathrm{~min}$. All IDI and FGD were conducted face to face or via an online video link. Interviewers and FGD facilitators summarised and verified throughout data collection to improve the validity of results. Meetings of Saving Brains innovators and partners on prioritising research in ECD and strategies for implementation of interventions were audio recorded and/or transcribed. Audio recordings of IDI, FGD and meetings were submitted to a third party for transcription. Members of the Saving Brains evaluation team conducted IDI (MKL, KMM and VC) and facilitated FGD (CJT, KMM, VC) alongside members of the Saving Brains Platform.

Qualitative data also included Saving Brains project progress reports; written narratives on implementation challenges and mitigation strategies.

\section{Qualitative analysis}

Written project documents and transcribed IDI and FGD were deidentified, imported and coded in NVivo V.11. Data were independently coded line by line by two members of the evaluation team (MKL, KMM). An inductive approach was used to create a coding framework, and thematic content analysis was undertaken to explore themes related to human resources and curricula content until saturation was reached. Inter-rater coding reliability was high on review of NVivo V.11 coding reports.

\section{Patient and public involvement}

This evaluation was conducted without direct patient involvement and they did not contribute to the interpretation of results or writing and editing of this document. However, families were frequently involved in different aspects of the design and interpretation of individual projects within Saving Brains including, but not limited to, the materials used in intervention delivery and methods for incentivising participation.

\section{RESULTS}

Overview: quantitative and qualitative results

Thirty-two of the 39 Seed and TTS projects included some aspect of RCEL (figure 1); the seven non-RCEL projects 


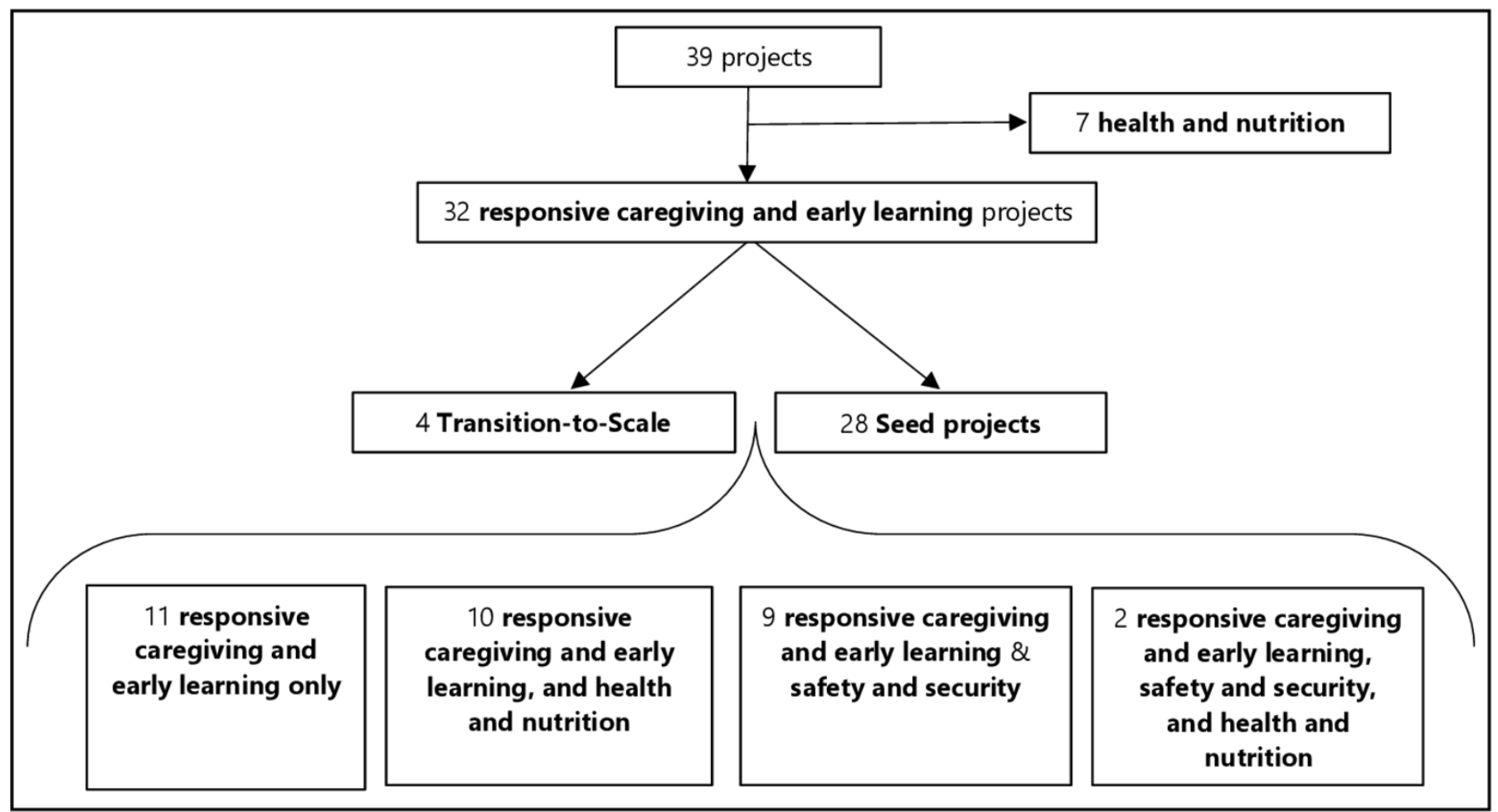

Figure 1 Project inclusion flow chart: inclusions and subsets of responsive care and early learning projects from the Saving Brains portfolio $(n=39)$.

were not included in this analysis. Of these 32 projects, $34 \%(\mathrm{n}=11)$ were stand-alone RCEL interventions and $66 \%(\mathrm{n}=21)$ were integrated with interventions in 'health and nutrition' (10 projects), 'security and safety' (9 projects) or both (2 projects) (figure 1$)$. Projects were implemented in 17 LMICs across four continents (see figure 2).

IDIs were conducted with $66 \%(\mathrm{n}=21)$ of Saving Brains project teams including all TTS projects. Emergent themes from the qualitative analysis are presented in table 1. Saving Brains TTS project leads provided quantitative data on these emergent themes (table 2).

\section{Human resources in ECD projects: themes and subthemes}

Three major human resource themes and 11 subthemes were identified (table 1).

\section{Characteristics/selection of workers}

Variation in workforce across the Saving Brains portfolio is summarised in figure 3 . The use of health or associate health professionals, such as community health workers, was common. Health professionals commonly delivered projects that included health and nutrition domains (figure 3A). Lay community members were also common as front-line workers across all project types.

Integrating ECD projects into existing programmes was identified by informants as a key challenge.

Early child development is harder than anything because of its integrated nature......we all decided that services had to be fully integrated.... and this has imposed an operational burden that is very complicated. (Saving Brains TTS project lead)
Approximately one-third of workers $(34 \%, n=11 / 32)$ had either only primary school level or no education (figure 3B). Tertiary-level education of workers was more common for RCEL projects which included health and nutrition domains $(42 \%, n=5)$ (figure $3 \mathrm{~B}$ ), likely reflecting the greater representation of healthcare professionals delivering these integrated interventions.

Soft skills including interpersonal and communication skills were identified as important by project leads.

We have learned a lot about the type of person that can fill the health promoter role. It is important that he/she is committed to the project, responsible, and loves working with kids, especially this age group. (Saving Brains Seed project lead)

Having a champion in the field is crucial for success...combination of strength and kindness; excellent interpersonal skills; problem solver; works with all stakeholders. (Saving Brains TTS project lead)

A key choice in ECD implementation was whether to use established or novel cadres of worker. In some projects, novel cadres of worker were recruited to support quality of implementation. However, limitations of this approach were acknowledged with regard to sustainability.

...even after identifying and training them there is no assurance that the government will take up the process. (Saving Brains TTS project lead)

Conversely, while a number of projects used pre-existing front-line workers, key informants also expressed concerns 


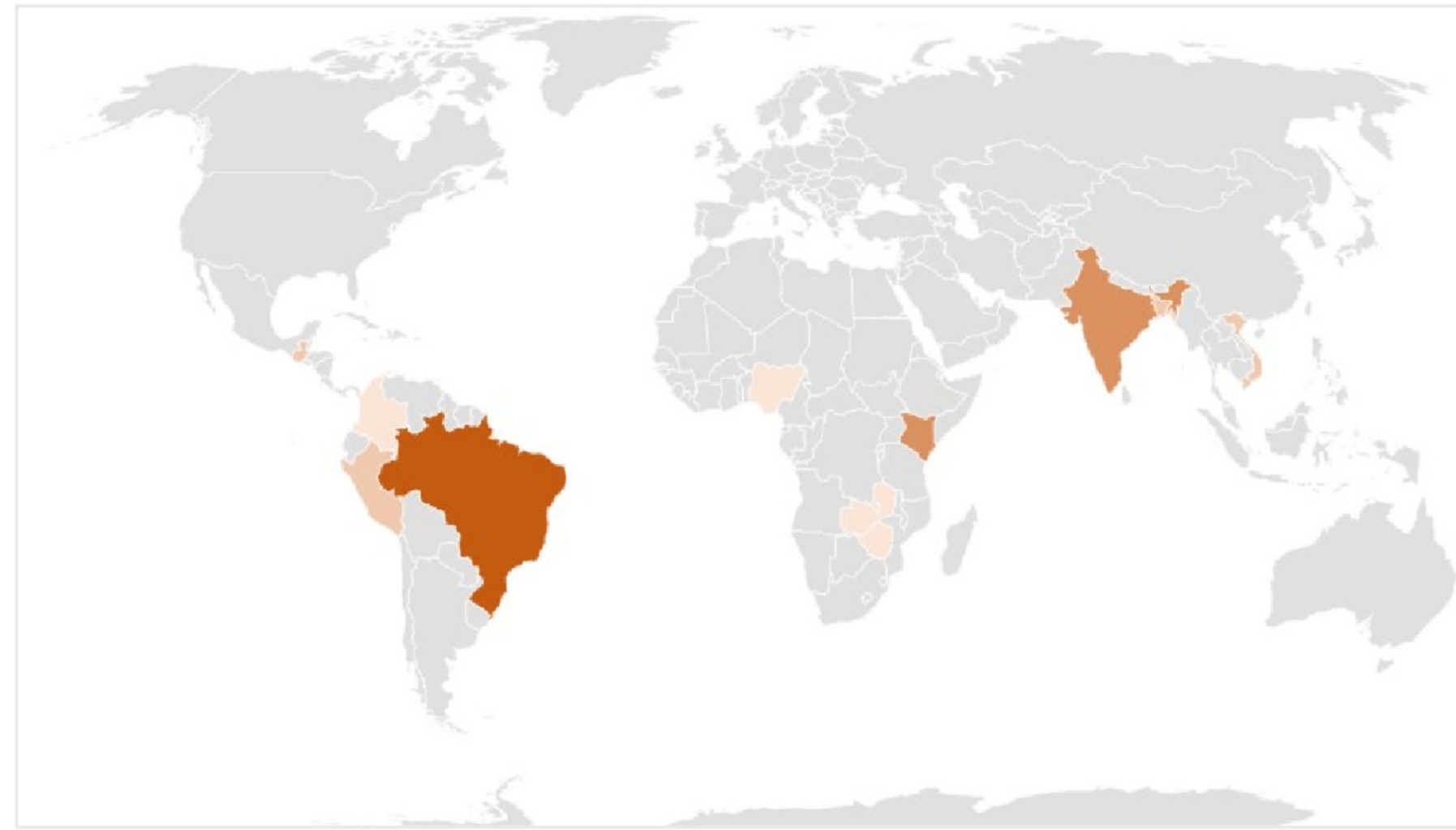

6 projects (Brazil)

4 projects (India, Kenya)

3 projects (Pakistan)

2 projects (Bangladesh, Guatemala, Peru, Vietnam)

1 project (Colombia, Democratic Republic of Congo, Ethiopia, Grenada, Jamaica, Nigeria, Rwanda, Zambia, Zimbabwe)

0 projects

Figure 2 Project implementation countries. Total number of countries of implementation $>32$ as one project implemented in three countries.

regarding direct control over recruitment, incentivisation, supervision and training when shared with a partner organisation (online supplementary appendix table D, International Centre for Diarrhoeal Disease Research, Bangladesh (ICDDR,B) and Universidade de São Paulo). The increased burden, change in focus and challenge in coordination for pre-existing salaried workers were also highlighted by experts and project teams.

It's a big challenge...you take a health worker and add a 24th task to her 23rd task, which are requested by six different funders with no coordination between any of them. (ECD lead for an international NGO)

They think [to themselves], 'I'm dealing with dengue and Zika and you expect me to play with a child for an hour.' (Saving Brains TTS project lead)

Provision of incentives based on performance (inducement) Overall, most $(61 \%)$ project workers were salaried (figure 3C). However, considering lay community member workers only, $20 \%$ of projects offered no incentives, and a further $20 \%$ offered only a contribution to expenses (figure 3C). Key informants expressed a range of opinions about remuneration of community health workers. Some cited elevated status within the community and personal satisfaction as a non-financial incentivisation. In contrast, concerns were expressed regarding sustainability and human rights implications of implementation models that relied on voluntary workers, who were often socially disadvantaged women. However, all health and most allied health professionals were salaried and financial remuneration for these groups was considered a key part of inducement.

Asking clinic staff to conduct the sessions meant additional tasks for them and they had to spend longer hours in the clinic. They therefore had expectations to be paid some wages for this extra task, but our goal was to integrate the activity into their daily routine hours to make it sustainable. (Saving Brains TTS project lead)

Staff recruitment and retention was a major recurring theme. Of the 2572 workers recruited to deliver ECD interventions across the Saving Brains RCEL projects, $2433(95 \%)$ completed initial training and, of those 
Table 1 Themes and subthemes from quantitative and qualitative data analyses for 32 Saving Brains projects, and 19 key informant in-depth interviews regarding human resources and curricula content for early child development (ECD) programming

\begin{tabular}{|c|c|c|}
\hline & Themes & Subthemes \\
\hline \multirow[t]{9}{*}{ Human resources } & \multirow{4}{*}{$\begin{array}{l}\text { 1. Characteristics/selection of } \\
\text { worker }\end{array}$} & 1.1 Health versus other sector \\
\hline & & 1.2 Integration with existing programmes \\
\hline & & 1.4 Professional versus lay worker \\
\hline & & 1.5 Qualities and qualifications \\
\hline & 2. Inducement and retention & 2.2 Impact on pre-existing workers \\
\hline & \multirow[t]{4}{*}{ 3. Training and supervision } & 3.1 Content of training \\
\hline & & 3.2 Flexibility versus fidelity \\
\hline & & 3.3 Education theory \\
\hline & & 3.4 Supportive relationships \\
\hline \multirow{5}{*}{ Curricula content } & \multirow{2}{*}{ 4. Content and components } & 4.3 Flexibility versus fidelity \\
\hline & & 4.4 Behaviour change \\
\hline & \multirow[t]{3}{*}{ 5. Delivery, duration and dosage } & 5.1 Adapting delivery to local context \\
\hline & & 5.2 Intervention duration and dosage \\
\hline & & 5.3 Retention of participants \\
\hline
\end{tabular}

trained, $2165(84 \%)$ ultimately delivered the intervention (figure 3D). Across the portfolio, retention was most challenging among salaried staff who were mostly health staff with $67 \%$ of salaried workers trained delivering the intervention (figure 3D). Specific reasons for drop-off were not available from existing data.

During programme planning, several teams described strategies including 'over-recruitment' to allow for anticipated staff attrition.

In this next phase, we trained many more promoters than we needed, approximately twice as many as we originally needed in order to have a healthy resource base. (Saving Brains Seed project lead)

It was hard to get [the staff], but we were very successful in keeping them. ... We paid them well which is something that I don't know that the government will be able to do. They also had a lot of support and a lot of training. They really appreciated all that they received from our team... (Saving Brains TTS project lead)

\section{Training and supervision}

A wide variation in supervision frequency, duration and ratios, and training structure and duration was seen across projects (table 3 ).

Training and supervision emerged as major themes during qualitative analysis (table 1). Within training, the need to address details of ECD curricula and a diverse range of related issues including pedagogy, strategies for managing the emotional load of work and administrative requirements, communication skills and problem-solving abilities were identified. Several key informants also highlighted the value of observational supervision.

...not only to see that content is delivered but that it is delivered in a way that parents will be responsive to.

(Saving Brains TTS project lead)

The importance of flexible training and supervision protocols that were feasible for staff who had multiple roles and were likely to be sustainable with scale-up was also emphasised.

Ongoing training including proficiency evaluations and feedback build confidence in participating community health workers to apply the tools and methodologies to deal with mothers and children. We have learned this over the years of work with community health workers and plan to systematize the work into teaching protocols as part of the transition to scale phase. (Saving Brains TTS project lead)

Key informants highlighted the need to develop formal structures for high-quality supportive training and supervision at all staff levels; this was particularly important in maintaining fidelity during intervention scale-up (online supplementary appendix table D). In addition, discussions emphasised the importance of peer support among workers (online supplementary appendix table D). 
Table 2 Description of the Saving Brains responsive care and early learning (RCEL) Transition-To-Scale projects: summary of human resources and curricula content ( $n=4$ projects)

\begin{tabular}{|c|c|c|c|c|}
\hline Project name & $\begin{array}{l}\text { Transition to scale } \\
\text { of an integrated } \\
\text { programme of } \\
\text { nutritional care } \\
\text { and psychosocial } \\
\text { stimulation } \\
\text { to improved } \\
\text { malnourished } \\
\text { children's } \\
\text { development }\end{array}$ & $\begin{array}{l}\text { An integrated intervention } \\
\text { targeted at deprived } \\
\text { preschool children in rural } \\
\text { areas }\end{array}$ & $\begin{array}{l}\text { Home visiting } \\
\text { programmes to improve } \\
\text { early child development } \\
\text { and maternal mental } \\
\text { health }\end{array}$ & $\begin{array}{l}\text { Saving Brains, Changing } \\
\text { Mindsets }\end{array}$ \\
\hline Lead institution & $\begin{array}{l}\text { International Centre } \\
\text { for Diarrhoeal } \\
\text { Disease Research, } \\
\text { Bangladesh } \\
\text { (ICDDR,B) }\end{array}$ & $\begin{array}{l}\text { Universidad de Los Andes } \\
\text { (UDLA) }\end{array}$ & $\begin{array}{l}\text { Faculdade de Medicina } \\
\text { da Universidade de São } \\
\text { Paulo (USP) }\end{array}$ & $\begin{array}{l}\text { Mobile Crèches for } \\
\text { Working Mothers' } \\
\text { Children (MC) }\end{array}$ \\
\hline Country & Bangladesh & Colombia & Brazil & India \\
\hline Vision/goal/objectives & $\begin{array}{l}\text { Integrate RCEL } \\
\text { intervention for } \\
\text { poor, underweight } \\
\text { children into routine } \\
\text { government health } \\
\text { services }\end{array}$ & $\begin{array}{l}\text { Improve quality of a pre- } \\
\text { existing public parenting } \\
\text { programme in a scalable } \\
\text { fashion }\end{array}$ & $\begin{array}{l}\text { Evaluate the efficacy and } \\
\text { cost-effectiveness of two } \\
\text { alternative platforms for } \\
\text { home visiting programme }\end{array}$ & $\begin{array}{l}\text { Demonstrate scalability } \\
\text { of workplace-based } \\
\text { childcare for children } \\
\text { of migrant construction } \\
\text { workers }\end{array}$ \\
\hline Participating children, $\mathrm{n}$ & 1597 & 2134 & 800 & 4845 \\
\hline \multicolumn{5}{|l|}{ Human resources } \\
\hline Type & $\begin{array}{l}\text { Associate health } \\
\text { professional }\end{array}$ & $\begin{array}{l}\text { Lay community member } \\
\text { as paraprofessional }\end{array}$ & $\begin{array}{l}\text { Community health } \\
\text { workers }(\mathrm{CHW}) \text { and child } \\
\text { development agents } \\
(\mathrm{CDA})\end{array}$ & Personal care worker \\
\hline Gender of workers & Majority female & Majority female & Exclusively female & Majority female \\
\hline Length of training & 15 days & 85 hours over 3.5 weeks & $\begin{array}{l}40 \text { hours initial (Reach Up) } \\
\text { and } 32 \text { hours refresher }\end{array}$ & 36 days \\
\hline $\begin{array}{l}\text { Workers recruited } \\
\text { (completing training, } \\
\text { delivering project), } n\end{array}$ & $354(320,168)$ & $171(171,171)$ & $15(15,13)$ & $139(83,67)$ \\
\hline Frequency of supervision & $\begin{array}{l}\text { Minimum once per } \\
\text { month. }\end{array}$ & Every 6 weeks & Once per week & $\begin{array}{l}\text { Six months rigorous, then } \\
\text { monthly }\end{array}$ \\
\hline \multicolumn{5}{|l|}{ Curricula content } \\
\hline Group versus individual & 2 or $4-5$ dyads & $\begin{array}{l}80 \% \text { group, } 20 \% \\
\text { individual }\end{array}$ & All individual & $\begin{array}{l}70 \% \text { group, } 30 \% \\
\text { individual }\end{array}$ \\
\hline Duration of intervention & 12 months & 11 months & 12 months & 3 months \\
\hline Average length of sessions & $50 \mathrm{~min}$ & 1 hour & 1 hour & 8 hours (full creche day) \\
\hline Sessions, $n$ & 25 & 55 & 24 & 75 \\
\hline $\begin{array}{l}\text { Frequency of contacts per } \\
\text { month }\end{array}$ & 2 & 3 & 2 & 25 \\
\hline
\end{tabular}

Continued 


\begin{tabular}{|c|c|c|c|c|}
\hline Curriculum & $\begin{array}{l}\text { Adaptation of Reach } \\
\text { Up }\end{array}$ & Adaptation of Reach Up & Adaptation of Reach Up & $\begin{array}{l}\text { Thematic curriculum on } \\
\text { school readiness skills }\end{array}$ \\
\hline Use of digital media & None & None & None & None \\
\hline Mentoring & Yes & Yes & Yes & Yes \\
\hline Problem solving & Yes & Yes & - & - \\
\hline Didactic & - & - & - & - \\
\hline Demonstrations & Yes & Yes & Yes & Yes \\
\hline Media & - & - & - & - \\
\hline Materials & Yes & - & Yes & - \\
\hline Published references & 214849 & 2150 & 2150 & 2151 \\
\hline
\end{tabular}

\section{Curricula content: themes and subthemes}

Two major themes and seven subthemes were identified with respect to curricula content (table 1).

\section{Content and components}

Improved understanding of the critical components of RCEL interventions was a major theme identified by key informants as crucial to sustainability and scale-up.

Many projects provided general descriptions of content (eg, parenting programme, responsive parenting, nutrition) or the original curriculum from which their project was developed (commonly the established Jamaican 'Reach Up' curricula) (table 2) ${ }^{19}$ However, for many, the critical components were less well defined and described. Specifically, details of activities for different ages or developmental stages, child health or nutrition components, behavioural change approaches used, pedagogy and materials were typically limited. Lack of an established and standardised framework for describing curricula content was identified by key informants as a barrier to improved reporting and understanding design factors responsible for impact.

The importance of formative research and piloting for development and adaptation of interventions to setting was highlighted.

Project development is also really important...these projects are not 'off-the-shelf' 'ready-to-go'. (ECD expert)

Additionally, the importance of balancing project flexibility, fidelity and content heterogeneity with clear, specific and structured curricula was emphasised.
The other determinant of success I would say is... we were able to develop a contextualized project, delivery product and processes. (Saving Brains Seed project lead)

Specific materials and activities often required guided cultural adaptation to maintain fidelity (online supplementary appendix table D). However, it is important to note that key informants placed equal emphasis on behaviour change mechanisms as well as on specific curricula activities and materials.

Key components [were] inspiration, confidence... empathy, attachment of mothers and children to the deliverer...assessment for change. (Saving Brains Seed project lead)

\section{Delivery, duration and dosage}

The importance of project delivery, duration and dosage emerged as a major theme in the analysis. Figure 4 summarises the method and duration of delivery of ECD interventions. The proportion using groups to deliver the intervention was highest among stand-alone RCEL projects and lowest among integrated approaches (figure 4A). Duration of sessions generally lasted longer for groups than individual visits (figure 4B).

ECD investigators reported that the decision regarding group or individual delivery approach was influenced more by context, efficiency and feasibility than effectiveness.

Our problem...was trying to do something that we thought was evidence based, but that was not a good 


\section{A}

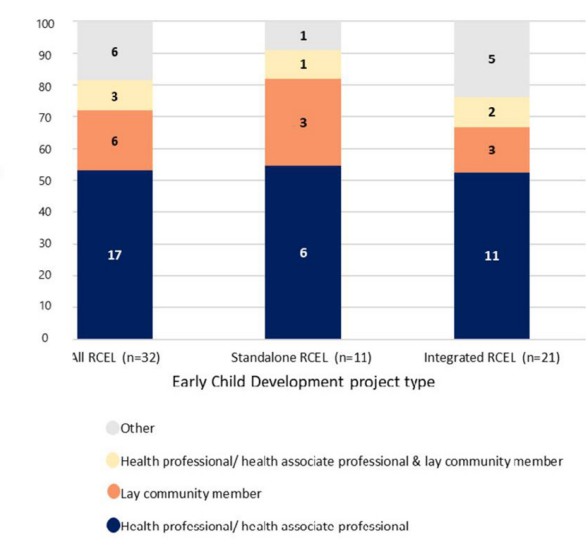

B

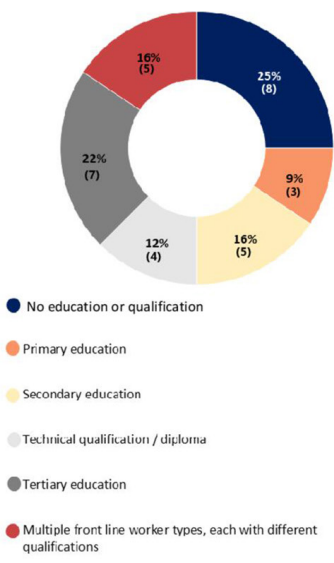

D

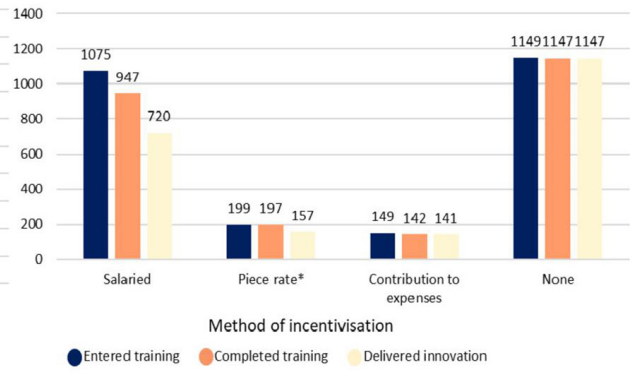

Figure 3 Occupation, incentivisation, qualification and retention of front-line workers among Saving Brains portfolio responsive care and early learning (RCEL) projects. (A) Occupation of front-line worker delivering RCEL projects by type of RCEL intervention project ( $n=32$ projects). No missing data $(n=32$ projects). Figures on bars represent number of projects. 'Other'=teaching professionals, social work professionals, personal care workers and combinations of occupation types. (B) Reported level of education/qualification of front-line workers across all RCEL projects ( $n=32$ projects). Data reported from Service Delivery Forms which report on the level of education or qualifications that front-line workers had (rather than what implementers felt that they needed). No missing data. (C) Incentivisation of front-line workers delivering RCEL projects according to cadre of worker ( $n=25$ projects). Total ' $n$ ' is greater than number of projects included $(n=25)$ as several projects used more than one occupation as workers. Piece rate=any irregular payment where pay is per task rather than fixed salary payment. (D) Retention of worker among RCEL projects according to method of incentivisation ( $n=29$ projects). Data reported from the Results-based Management and Analysis Framework (online supplementary appendix table A) reported from each project. Missing data from three projects. Piece rate=any irregular payment where pay is per task rather than fixed salary payment.

fit with the socio-political structures and the way people are comfortable in trying new things. (Saving Brains Seed project lead)

Key informants highlighted 'dosage' of the intervention as an important design decision. The median number of project sessions delivered, length of sessions and length of intervention ranged broadly (table 4 ).
The majority $(60 \%, \mathrm{n}=19)$ of projects were primarily targeted at the child or caregiver level as opposed to targeting families or the community more broadly. Geographical, political and economic factors were important in engaging target populations.

...some mothers find it difficult to come to the clinics for the fortnightly sessions. The reasons were lack

\begin{tabular}{|c|c|c|c|}
\hline & Median & Range & IQR \\
\hline Number of days in training $(n=31)$ & 10 & $0-90$ & $5-13.6$ \\
\hline Frequency of supervision $(n=28)$ & 2 per month & $0-10$ & $1.5-4$ \\
\hline Duration of supervision $(n=27)$ & 2 hours & $0-8$ & $1-4$ \\
\hline
\end{tabular}

Data from Saving Brains standardised programme reporting 'Service Delivery Form'. Missing data for one project on number of days in training and number of trainees per workshop, four projects did not report on frequency of supervision and five projects on duration. Twelve projects did not report on the ratio of supervisor to trainee. 


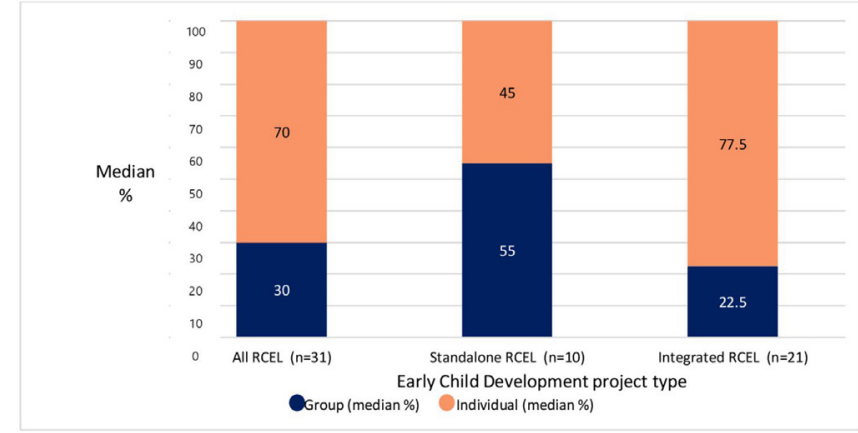

B

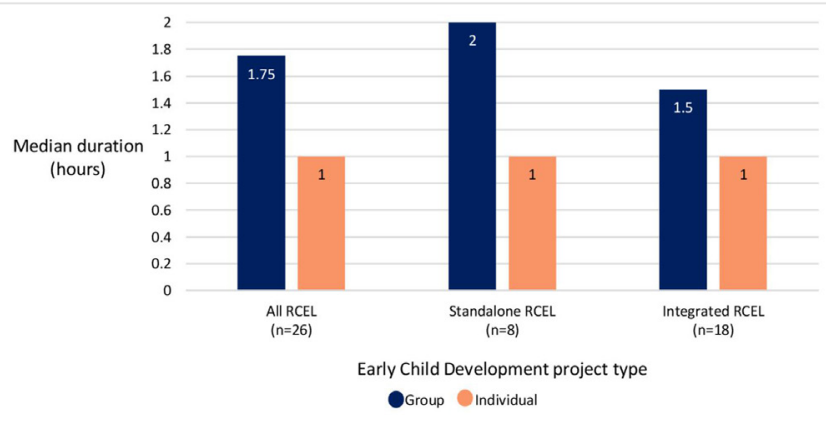

Figure 4 Method and duration of delivery of intervention curricula among Saving Brains portfolio responsive care and early learning (RCEL) project. (A) Method of project delivery: group versus individual by type of RCEL intervention project $(\mathrm{n}=31$ projects). Missing data from one project. (B) Median duration of project sessions comparing projects delivering curricula in group versus individual sessions by type of RCEL intervention project ( $n=26$ projects). Missing data from six projects.

of time, distance from the clinic, not allowed by the father or grandparents of the child and occasionally travelling outside the area. (Saving Brains TTS project lead)

Project teams used a range of methods to incentivise caregivers to attend sessions. One TTS team trialled both provision of oil supplementation and 'motivational meetings' (table 2, ICDDR,B); both methods were found to be effective but motivational meetings were adopted due to sustainability.

\section{DISCUSSION}

This is the first paper to report on workforce data from a large multicountry child development portfolio, including 32 RCEL projects with 2165 workers delivering interventions across 17 LMICs. This analysis addresses human resources and curricula content for implementation at scale; it is noted that these factors do not stand in isolation but interact with each other and other programme design factors as well as with local contexts. Radner et als exploration of the Saving Brains portfolio highlighted that workforce decisions around delivery of RCEL programmes can have substantial bearings on programme sustainability and impact. In this paper, we built on this to further probe specifics of workforce choices in ECD programme implementation, particularly from a health sector perspective. ${ }^{11}{ }^{21}$ Resultant themes and subthemes resonate with and extend existing literature regarding workforce choices, particularly the community health workforce, for programme implementation in LMIC settings.

Workforce factors are one of the most critical impediments to implementation at scale. This is well recognised for ECD programmes, especially given intersectoral complexities. Our results suggest that while challenges exist for integrating ECD into existing services, introducing novel cadres of worker for stand-alone ECD programmes may be also challenging at scale. Within this analysis, challenges related to adding ECD workstreams to the existing workload of established front-line workers were clearly reported and may have contributed to poorer retention of salaried health workers, alongside rotation of health workers. This finding has been mirrored across the implementation literature in other areas of global health; for example, an economic analysis of community-based maternal and newborn care across seven countries highlighted trade-offs between improved cost-effectiveness associated with use of existing multipurpose workers and difficulties related to overburdening those workers. ${ }^{25-29}$

Ongoing supportive supervision, not just initial training, was found to be crucial to intervention quality and fidelity, as has been found in global health more broadly. For example, quality supervision was emphasised as central to preservation of project quality as well as worker motivation in the economic analysis of maternal and newborn care mentioned above, and was examined in more detail in several of these evaluations, including the cluster randomised controlled Goodstart (III) trial of maternal and newborn care in South Africa. ${ }^{2630}$ Similarly, supervision and training, and particularly the potential of e-supervision/training, were highlighted as key concerns

Table 4 Summary of project sessions including duration and intensity among responsive care and early learning Saving Brains projects $(n=32)$

\begin{tabular}{|c|c|c|c|}
\hline & Median & Range & IQR \\
\hline Total length of intervention $(n=26)$ & 12 months & $1-24$ months & 8-12 months \\
\hline
\end{tabular}

Data from Saving Brains standardised programme reporting 'Service Delivery Form'. Missing data on number of project sessions for three projects, and on total length of intervention and length of sessions for six projects. 
for project feasibility in a review of interventions for children with intellectual disabilities ${ }^{31}$ and additionally were found to be critical for sustainable scale and impact in similar studies, such as Programme for Improving Mental Health Care and a follow-up study of a cluster randomised trial of a psychosocial ECD project in Colombia. ${ }^{27} 3233$

The challenge of retention of workers emerged as an important theme and is also not isolated to ECD. Within the Saving Brains portfolio, strategies used to mitigate against poor retention echoed findings in other global health implementation research, including: overrecruitment, fast-track training and provision of highquality training and supervision. ${ }^{27} 3033$ Andrew et al suggest designing interventions according to geographical practicalities and other contextual factors to mitigate staff turnover, and thus optimise project quality and impact. $^{32}$ There is appetite for shared learning to help tackle the human resource challenges highlighted in this paper, and resources such as the Early Childhood Workforce Initiative provide a useful platform for ECD policymakers and programmers globally to work together. ${ }^{34} 35$

Regarding essential ECD intervention curricula and components for scale-up, commonalities were seen among the larger TTS projects which add to previous literature on this topic. ${ }^{3}{ }^{12}$ However, there is no agreed standard package for ECD set out by the United Nations, contributing to project heterogeneity and precluding clear guidance for policymakers and programmers on ECD intervention content. This lack of standardised content is in contrast to more biomedical programmes, such as antenatal and postnatal care packages, as well as broader mental health and nutrition programmes which, though similar to ECD in their intersectoral nature, do have some standardised content, such as the WHO and UNICEF's Infant and Young Child Feeding approach. ${ }^{25} 3637$ While lack of description of intervention content in this portfolio hinders specific recommendations for a standardised ECD curriculum, our findings suggest that the focus of a standardised ECD curriculum should be on engaging parents in activities which promote development, rather than providing information on developmental milestones, as is seen in many countries.

Even with a standard package, contextualisation would be important, and our findings underline the need for formative research. Across the Saving Brains portfolio, there was a noticeable lack of in-depth description of curricula content, despite key informants highlighting this as important for sustainability. ${ }^{12}{ }^{13}$ A framework for describing contextualised content of RCEL projects using, for example, parameters described by Aboud and Yousafzai (information, performance, problem solving, social support, materials and media), would provide clarity in the literature and strengthen programme comparison and evaluation. ${ }^{12} 38$ Further, as the Nurturing Care Framework proposes, delineating ECD programmes more clearly into universal, targeted and indicated packages to respond to the specific needs of children at particular developmental risk or with developmental disabilities would support better inclusion of children who otherwise risk not being reached by universal or conventional service models. ${ }^{79-41}$ As Boggs et al highlight, improved developmental monitoring is critical, and ECD workers have a vital role to play in identifying the young children most at risk of developmental difficulty and referring for ECD intervention, as well as in intervention delivery. ${ }^{19}$ While there is little published literature on early intervention to improve health and developmental outcomes for children with disabilities in LMICs, trials are underway and emerging models that have been adapted and that are being trialled in the context of the Zika epidemic may be informative. $^{42} 43$

Regarding delivery strategy, group sessions were frequently favoured across the portfolio, notably based on increased practicality, efficiency and acceptability, rather than increased effectiveness. ${ }^{21}$ Previous evidence for both ECD and health programmes supports the use of a combination of home visits and group sessions as more effective in terms of information consolidation and parental behavioural change. ${ }^{812}{ }^{44}$ Future ECD research would benefit from an alignment of outcomes, where feasible, to ensure comparability in assessment of effectiveness. Intervention dosage was variable across the portfolio and the need for flexibility in this when adapting to different contexts, for example, during implementation of the 'Reach Up' package in Brazil, frequently emerged during analysis. ${ }^{45}$ Dosage variability was similarly reported during the Goodstart (III) trial and was attributed to contextual and workforce factors including occupation, remuneration and community recognition of workers. ${ }^{30}$

\section{Strengths and limitations}

Many of the limitations of this evaluation are common to ECD programming more broadly. Several processrelated metrics were not commonly reported including coverage, equity and cost-effectiveness, likely influenced by the small-scale and 'proof of concept' nature of most projects. ${ }^{33}$ The donor-facing system of data collection and reporting within the portfolio may have introduced bias, with investigators feeling obliged to report positively, however the open learning culture within the Saving Brains Platform acted to substantially reduce this. Grant awardees were selected by GCC and so projects and their aims may reflect funder priorities. The diversity in human resources and curricula content between projects made it difficult to draw conclusions for individual RCEL programme implementation from the portfolio-level evaluation outcomes. Impact data were not available for most projects at the time of the evaluation and so assessment of impact was not included. Enhancing linkages between implementation processes and impacts within this portfolio and more broadly has the potential to strengthen evidence to inform policy and programming. Additionally, while this paper describes design decisions, there was not scope to explore the reasons behind these decisions. Exploration of these reasons may contribute to stronger and clearer evidence, policy and programming. 


\section{CONCLUSION}

We have reported on the largest study to date of workforce and curricula content for ECD from a large and varied portfolio of 32 projects, providing a detailed description and new synthesis about implementation challenges and enablers for ECD programming. Despite heterogeneity of projects, clear themes have emerged with parallels to LMIC programmatic learning in other areas, such as global mental health and nutrition. Development of a more standardised package or planning guide for ECD programmes would mitigate some of the challenges reported here, but programmes still need to be adapted to context. Carrying out and learning from such adaptation could be supported by a common framework for describing content and delivery strategies. More systematic evaluations of implementation costs, including worker costs, will be essential inputs for planning of routine ECD programmes, within and beyond the health sector. Further research investigating associations between human resource and curricula content choices and, importantly, impact is needed.

\section{Author affiliations}

${ }^{1}$ Maternal, Adolescent, Reproductive and Child Health Centre, London School of Hygiene and Tropical Medicine, London, UK

${ }^{2}$ Population Health Sciences, University of Bristol, Bristol, UK

${ }^{3}$ Economics Department, Universidad de Los Andes, Bogota, Colombia

${ }^{4}$ Centro de Estudios de Desarrollo Economico (CEDE), Universidad de Los Andes,

Bogota, Colombia

${ }^{5}$ Maternal and Child Health Intervention Research Group, London School of Hygiene and Tropical Medicine, London, UK

${ }^{6}$ Northern School of Paediatrics, Newcastle upon Tyne, UK

${ }^{7}$ Departamento do Pediatria, Faculdade de Medicina, Universidade de São Paulo, São Paulo, Brazil

${ }^{8}$ Department of Mental Health and Substance Abuse, World Health Organization, Geneva, Switzerland

${ }^{9}$ Bernard Van Leer Foundation, The Hague, Netherlands

${ }^{10}$ Maternal and Child Health Division, ICDDR,B, Dhaka, Bangladesh

${ }^{11}$ Children's Investment Fund Foundation, London, United Kingdom

${ }^{12}$ Department of Paediatrics and Child Health, Muhimbili University of Health and Allied Sciences, Dar es Salaam, Tanzania

${ }^{13}$ Murdoch Children's Research Institute, Melbourne, Victoria, Australia

${ }^{14}$ Munk School of Global Affairs and Public Policy, University of Toronto, Toronto, Ontario, Canada

${ }^{15}$ Center on the Developing Child, Harvard University, Cambridge, Massachusetts, USA

${ }^{16}$ Sector IV, Mobile Crèches, New Delhi, India

${ }^{17}$ Grand Challenges Canada, Toronto, Ontario, Canada

${ }^{18}$ Neonatal Medicine, University College London Hospitals NHS Foundation Trust, London, United Kingdom

${ }^{19}$ Social Aspects of Health across the Life Course, MRC/UVRI \& LSHTM Uganda Research Unit, Entebbe, Uganda

Twitter Maya Kohli-Lynch @mayakohlilynch, Victoria Ponce Hardy @vponcehardy, Sunil S Bhopal @sunilbhop, Rob Hughes @R_Hughes1, Kate M Milner @ KateMcMilner, Karlee L Silver @karleesilver, Joy E Lawn @joylawn and Cally J Tann @callytann

Acknowledgements We thank all the investigators, participants and researchers involved in projects included in the Saving Brains portfolio and evaluation. We thank Grand Challenges Canada as funder of unpublished data. We thank the Expert Advisory Group (Pia Britto, Tarun Dua, EG, Sally Grantham-McGregor, Melissa Gladstone, JH, RH, KM, JR, Muneera Rasheed, KS, Arjun Upadhyay) for their guidance; and we are grateful to Claudia da Silva for administrative assistance.
Contributors The first draft of the paper was undertaken by CJT, MKL and VPH. Other specific contributions were made by RBS, SB, AB, VC, EG, JH, RH, KM, KMM, JR, SS, KS and JEL. All authors reviewed and agreed on the final manuscript.

Funding This paper has been made possible by funding support from the Bernard van Leer Foundation. The Saving Brains impact and process evaluation was funded by Grand Challenges Canada. Grand Challenges Canada is funded by the Government of Canada.

Disclaimer The authors alone are responsible for the views expressed in this article and they do not necessarily represent the views, decisions or policies of the institution with which they are affiliated.

Map disclaimer The depiction of boundaries on this map does not imply the expression of any opinion whatsoever on the part of BMJ (or any member of its group) concerning the legal status of any country, territory, jurisdiction or area or of its authorities. This map is provided without any warranty of any kind, either express or implied.

\section{Competing interests None declared.}

Patient and public involvement Patients and/or the public were not involved in the design, or conduct, or reporting, or dissemination plans of this research.

Patient consent for publication Not required.

Ethics approval The study was approved by the London School of Hygiene and Tropical Medicine Ethics Committee (16001/RR/11202). Deidentified data were used in this analysis.

Provenance and peer review Not commissioned; externally peer reviewed.

Data availability statement All data relevant to the study are included in the article or uploaded as supplementary information. Supplementary data have been published online and may also be accessed by emailing cally.tann@|shtm.ac.uk.

Open access This is an open access article distributed in accordance with the Creative Commons Attribution Non Commercial (CC BY-NC 4.0) license, which permits others to distribute, remix, adapt, build upon this work non-commercially, and license their derivative works on different terms, provided the original work is properly cited, appropriate credit is given, any changes made indicated, and the use is non-commercial. See: http://creativecommons.org/licenses/by-nc/4.0/.

\section{ORCID iDs}

Maya Kohli-Lynch http://orcid.org/0000-0003-1108-6383

Sunil S Bhopal http://orcid.org/0000-0003-1229-781X

Cally J Tann http://orcid.org/0000-0003-0131-4952

\section{REFERENCES}

1 United Nations. Transforming our world: the 2030 Agenda for Sustainable Development [online], 2015. Available: https://sustaina bledevelopment.un.org/post2015/transformingourworld

2 Every Woman Every Child. The global strategy for women's, children's and adolescents' health (2016-2030). New York, NY 2015.

3 Daelmans B, Black MM, Lombardi J, et al. Effective interventions and strategies for improving early child development. BMJ 2015;351:h4029.

4 Yousafzai AK, Obradović J, Rasheed MA, et al. Effects of responsive stimulation and nutrition interventions on children's development and growth at age 4 years in a disadvantaged population in Pakistan: a longitudinal follow-up of a cluster-randomised factorial effectiveness trial. Lancet Glob Health 2016;4:e548-58.

5 Engle PL, Black MM, Behrman JR, et al. Strategies to avoid the loss of developmental potential in more than 200 million children in the developing world. Lancet 2007;369:229-42.

6 Britto PR, Lye SJ, Proulx K, et al. Nurturing care: promoting early childhood development. Lancet 2017;389:91-102.

7 World Health Organisation. Nurturing care framework [online], 2018. Available: https://www.who.int/maternal_child_adolescent/child/ nurturing-care-framework/en/

8 Engle PL, Fernald LCH, Alderman H, et al. Strategies for reducing inequalities and improving developmental outcomes for young children in low-income and middle-income countries. Lancet 2011;378:1339-53.

9 Aboud FE, Yousafzai AK, Nores M. State of the science on implementation research in early child development and future directions. Ann N Y Acad Sci 2018;1419:264-71. 
10 Yousafzai AK, Aboud F. Review of implementation processes for integrated nutrition and psychosocial stimulation interventions. Ann N Y Acad Sci 2014;1308:33-45.

11 Neuman M, Kimberly J, Chua P. A review of the literature: early childhood care and education (ECCE) personnel in low- and middleincome countries. Paris: UNESCO, 2015.

12 Aboud FE, Yousafzai AK. Global health and development in early childhood. Annu Rev Psychol 2015;66:433-57.

13 Frongillo EA, Tofail F, Hamadani JD, et al. Measures and indicators for assessing impact of interventions integrating nutrition, health, and early childhood development. Ann N Y Acad Sci 2014;1308:68-88.

14 Darmstadt GL, Lombardi J, Black MM, et al. Early childhood development: the foundation of sustainable development. The Lancet 2017;389:9-11.

15 Yousafzai A, Aboud F, Nores M, et al Special Issue: Implementation Research and Practice for Early Childhood Development. In: Annals of the new York Academy of sciences, 2018.

16 Milner KM, Bernal Salazar R, Bhopal S, et al. Contextual design choices and partnerships for scaling early child development programmes. Arch Dis Child 2019;104:S3-12.

17 Arregoces L, Hughes R, Milner KM, et al. Accountability for funds for nurturing care: what can we measure? Arch Dis Child 2019;104:S34-42.

18 Milner KM, Bhopal S, Black M, et al. Counting outcomes, coverage and quality for early child development programmes. Arch Dis Child 2019;104:S13-21.

19 Boggs D, Milner KM, Chandna J, et al. Rating early child development outcome measurement tools for routine health programme use. Arch Dis Child 2019;104:S22-33.

20 Cavallera V, Tomlinson M, Radner J, et al. Scaling early child development: what are the barriers and enablers? Arch Dis Child 2019;104:S43-50.

21 Radner JM, Ferrer MJS, McMahon D, et al. Practical considerations for transitioning early childhood interventions to scale: lessons from the saving brains portfolio. Ann N Y Acad Sci 2018;1419:230-48.

22 Milner K, Kohli-Lynch M, Tann C, On behalf of the Expert Advisory Group and Saving Brains Platform. Saving brains portfolio impact and process evaluation report. London, United Kingdom: London School of Hygiene \& Tropical Medicine, 2016.

23 Moore GF, Audrey S, Barker M, et al. Process evaluation of complex interventions: medical Research Council guidance. $B M J$ 2015;350:h1258.

24 International Standard Classification of Occupations. ISCO-08. Geneva: International Labour Office, 2012.

25 Lawn JE, Bhutta ZA, Wall SN, et al. Cadres, content and costs for community-based care for mothers and newborns from seven countries: implications for universal health coverage. Health Policy Plan 2017;32:i1-5

26 Daviaud E, Owen H, Pitt C, et al. Overview, methods and results of multi-country community-based maternal and newborn care economic analysis. Health Policy Plan 2017;32:i6-20.

27 Mendenhall E, De Silva MJ, Hanlon C, et al. Acceptability and feasibility of using non-specialist health workers to deliver mental health care: stakeholder perceptions from the prime district sites in Ethiopia, India, Nepal, South Africa, and Uganda. Soc Sci Med 2014;118:33-42.

28 Tomlinson M, Hunt X, Rotheram-Borus MJ. Diffusing and scaling evidence-based interventions: eight lessons for early child development from the implementation of perinatal home visiting in South Africa. Ann N Y Acad Sci 2018;1419:218-29.

29 Black RE, Taylor CE, Arole S, et al. Comprehensive review of the evidence regarding the effectiveness of community-based primary health care in improving maternal, neonatal and child health: 8. summary and recommendations of the expert panel. J Glob Health 2017;7:010908

30 Daviaud E, Nkonki L, ljumba P, et al. South-Africa (Goodstart III) trial: community-based maternal and newborn care economic analysis. Health Policy Plan 2017;32:i53-63.

31 Reichow B, Servili C, Yasamy MT, et al. Non-Specialist psychosocial interventions for children and adolescents with intellectual disability or lower-functioning autism spectrum disorders: a systematic review. PLoS Med 2013;10:e1001572.

32 Andrew A, Attanasio O, Fitzsimons E, et al. Impacts 2 years after a scalable early childhood development intervention to increase psychosocial stimulation in the home: a follow-up of a cluster randomised controlled trial in Colombia. PLoS Med 2018:15:e1002556.

33 Lund C, Tomlinson M, de Silva M, et al. Prime: a programme toReduce the treatment gap for mental disorders in five low- and middle-income countries. PLOS One 2012;9.

34 Early childhood workforce initiative, 2019. Available: https://www.earl ychildhoodworkforce.org/

35 Mitter R, Putcha V. Strengthening and supporting the early childhood workforce: training andprofessional development. Washington DC: Results for Development, 2018.

36 World Health Organisation. Nutrition - Infant and young child feeding 2019, 2019. Available: https://www.who.int/nutrition/publications/ infant feeding/en/

37 World Health Organisation. Mental health 2019, 2019. Available: https://www.who.int/mental_health/en/

38 Yousafzai AK, Rasheed MA, Siyal S. Integration of parenting and nutrition interventions in a community health program in Pakistan: an implementation evaluation. Ann N Y Acad Sci 2018;1419:160-78.

39 Yousafzai AK, Lynch P, Gladstone M. Moving beyond prevalence studies: screening and interventions for children with disabilities in low-income and middle-income countries. Arch Dis Child 2014;99:840-8.

40 Kuper H, Smythe T, Duttine A. Reflections on health promotion and disability in low and middle-income countries: case study of ParentSupport programmes for children with congenital Zika syndrome. Int $J$ Environ Res Public Health 2018;15:1-4.

41 Zuurmond M, Nyante G, Baltussen M, et al. A support programme for caregivers of children with disabilities in Ghana: understanding the impact on the wellbeing of caregivers. Child Care Health Dev 2019;45:45-53.

42 Benfer KA, Novak I, Morgan C, et al. Community-Based parentdelivered early detection and intervention programme for infants at high risk of cerebral palsy in a low-resource country (learning through everyday activities with parents (LEAP-CP): protocol for a randomised controlled trial. BMJ Open 2018;8:e021186.

43 ISRCTN Current Controlled Trials [Internet].. Improving early detection and intervention for younginfants at high risk of neurodevelopmental delay and disability in Uganda London. BioMed Central, 2018. http://www.isrctn.com/ISRCTN44380971

44 Rockers PC, Bärnighausen T. Interventions for hiring, retaining and training district health systems managers in low- and middle-income countries. Cochrane Database Syst Rev 2013;4:CD009035.

45 Smith JA, Baker-Henningham H, Brentani A, et al. Implementation of reach up early childhood parenting program: acceptability, appropriateness, and feasibility in Brazil and Zimbabwe. Ann N Y Acad Sci 2018;1419:120-40.

46 Yousafzai AK, Rasheed MA, Daelmans B, et al. Capacity building in the health sector to improve care for child nutrition and development. Ann N Y Acad Sci 2014;1308:172-82.

47 Black MM, Walker SP, Fernald LCH, et al. Early childhood development coming of age: science through the life course. Lancet 2017;389:77-90

48 Hamadani J, Mehrin S, Tofail F, et al. Integrating an early childhood development programme into the Bangladeshi primary health care services: a cluster randomised trial. Lancet Glob Health 2018.

49 Hamadani JD, Nahar B, Huda SN, et al. Integrating early child development programs into health and nutrition services in Bangladesh: benefits and challenges. Ann N Y Acad Sci 2014:1308:192-203.

50 Attanasio O, Baker-Henningham $\mathrm{H}$, Bernal R, et al. Early stimulation and nutrition: the impacts of a scalable intervention. NBER Working Paper 2018.

51 Bajaj M, Sharma S. Scaling-up early childhood centres for migrant construction workers' children in India. Early Childhood Matters 2016;125:74-9. 